\title{
Clinical profile and outcome of children with acute bacterial meningitis in a tertiary care centre in eastern Nepal

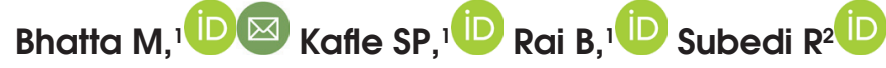

${ }^{1}$ Mukesh Bhatta; 'Shyam Prasad Kafle; 'Basant Rai; Assistant Professor, Department of Paediatrics and Adolescent Medicine, B.P. Koirala Institute of Health Sciences, Dharan, Sunsari, Nepal; ${ }^{2}$ Rejeena Subedi, Lecturer, Department of Child Health Nursing, Hamro School of Nursing, Biratnagar, Morang, Nepal.

\begin{abstract}
Background: Bacterial meningitis is a severe infection of the central nervous system with varied clinical presentations. It is associated with substantial mortality and morbidity.

Objectives: The objective of this study was to assess the clinical profile, including the clinical features, laboratory and radiological parameters, clinical course, treatment, response to treatment, complications, and outcome of children at discharge.

Methods: A prospective observational study was conducted among 52 inpatient children of acute bacterial meningitis aged one month to 14 years over a period of six months. The patients were enrolled during admission and followed up daily till discharge. Socio-demographic, clinical, and diagnostic details and outcomes were recorded and analysed using statistical package for social sciences version 20.

Results: The median age of the patients was two years with male to female ratio of 2:1. Fever (45, 87\%), vomiting (37, $71 \%)$, seizure $(33,64 \%)$ and headache $(22,46 \%)$ were the most common symptoms. The cerebrospinal fluid culture was positive in three $(6 \%)$ cases. Complications were seen in 20 (39\%) patients including four (7.7\%) deaths. Patients with prolonged fever, malnutrition, loss of consciousness, ear discharge, presence of meningeal signs, abnormal pupil, high cerebrospinal fluid protein, positive cerebrospinal fluid, and blood culture, low blood $\mathrm{pH}$, and hyperlactataemia were significantly associated with complications $(p<0.05)$.

Conclusion: Factors like malnutrition, longer duration of fever, and abnormal neurological and laboratory findings were associated with higher rates of complications.
\end{abstract}

Key words: Cerebrospinal fluid; Coma; Complications; Intracranial pressure; Seizures.

\section{Access this article online}

Website: www.jkmc.com.np

DOI: https://doi.org/10.3126/jkmc.v10i2.40016

\section{HOW TO CITE}

Bhatta M, Kafle SP, Rai B, Subedi R. Clinical profile and outcome of children with acute bacterial meningitis in a tertiary care centre in eastern Nepal. J Kathmandu Med Coll. 2021;10(2):64-73.

Address for correspondence

\section{Dr. Mukesh Bhatta}

Assistant Professor,

Department of Paediatrics and Adolescent Medicine,

B.P. Koirala Institute of Health Sciences,

Dharan, Sunsari, Nepal.

E-mail:mukacebhatta@gmail.com

Copyright $\odot 2021$ Journal of Kathmandu Medical College (JKMC)

ISSN: 2019-1785 (Print), 2091-1793 (Online)

(i) (5) This work is licensed under a Creative Commons Attribution-Non Commercial 4.0 International License.

\section{INTRODUCTION}

eningitis is an infection of meninges caused 1 by access of different bacteria to subarachnoid space. Mortality and morbidity of bacterial meningitis are significant, even with appropriate treatment. ${ }^{1}$ Case fatality rate of bacterial meningitis is $10 \%$ in developed countries, while it ranges from $22-73 \%$ in low- and middle-income countries. ${ }^{2,3}$ Clinical features in older children include fever, headache, vomiting, and seizures, while younger children and infants have nonspecific subtle signs and symptoms like fever, lethargy, irritability, poor feeding, vomiting, diarrhoea, respiratory distress, seizures, and bulging fontanelle. ${ }^{4}$ The diagnosis of bacterial meningitis is made by analysis of Cerebro-spinal fluid (CSF) for total leukocyte count, glucose, protein, gram stain, and culture. However, prior use of antibiotics can change the levels of these parameters and may mask the diagnosis. ${ }^{5,6}$ Therefore, it is important to assess clinical 
and laboratory parameters for making the diagnosis of bacterial meningitis. A better understanding of these parameters would help in early diagnosis, management, prognostication, and prevention of complications. The study was undertaken with the objective of assessing the clinical profile, including the presenting clinical features, laboratory and radiological parameters, clinical course, treatment, response to treatment, complications, and outcome of children with acute bacterial meningitis.

\section{METHODOLOGY}

This was a prospective observational study carried out at the paediatric ward and Paediatric Intensive Care Unit (PICU) of B.P. Koirala Institute of Health Sciences (BPKIHS), a tertiary care referral centre in eastern Nepal. Data collection was done over a period of six months from June 2020 to December 2020 after the ethical clearance was obtained from the Institutional Review Committee (IRC) of BPKIHS (Ref. 410/076/077-IRC dated on $4^{\text {th }}$ June 2020), and informed written consent was obtained from the parents in the local language before each enrolment. Patients from one month to 14 years of age admitted to the Paediatric ward or PICU of BPKIHS with a diagnosis of acute bacterial meningitis by clinical and/or laboratory parameters, and whose parents gave consent were included in the study. However, patients who had received more than three days of intravenous antibiotics in an outside hospital, those with underlying chronic neuromuscular illness (which could obscure or alter the obvious neurologic signs of meningitis), patients who Left Against Medical Advice (LAMA), and patients' whose parents refused to participate in the study were excluded from the study. The diagnosis of meningitis was based on clinical findings and/or CSF analysis. Children older than two years of age presenting with a triad of fever, headache, and vomiting along with other symptoms like seizure, and presence of meningeal signs like neck rigidity, Kernig's sign, or Brudzinski sign were suspected as acute bacterial meningitis. Similarly, children younger than two years, presenting with fever, vomiting, excessive cry, poor feeding, abnormal behaviour, lethargy, abnormal body movement, and a bulged fontanelle were suspected as having acute bacterial meningitis. All the clinically suspected cases underwent lumbar puncture for CSF analysis. Parents whose children had clinical features of acute bacterial meningitis but refused to do lumbar punctures were excluded from the study. Cerebrospinal fluid parameters showing polymorphonuclear pleocytosis (>100 leucocytes per cubic $\mathrm{mm}$ with predominantly polymorphonuclear cells) with or without cerebrospinal fluid biochemistry suggestive of acute bacterial meningitis (CSF glucose $<40 \mathrm{mg} / \mathrm{dl}$ or $<50 \%$ of the serum glucose levels and CSF proteins $>100 \mathrm{mg} / \mathrm{dl}$ ) were taken as diagnostic parameters. However, for patients in whom prior use of antibiotics were done (defined as the use of intravenous antibiotics for more than 24 hours prior to lumbar puncture), a combination of clinical features, total leukocyte count of more than 11,000 cells/cubic $\mathrm{mm}$ in complete blood count along with CSF leukocytes $>10$ / cu $\mathrm{mm}$ were considered as acute bacterial meningitis and treated. Patients with focal neurological defects, increasing head circumference, multiple episodes of seizures even after three days of antimicrobials, persistent fever for more than five days and persistently positive CSF culture had a Computed Tomography (CT) scan head done. Similarly, other relevant haematological tests like complete blood count, blood culture, blood glucose, serum electrolytes, and renal function tests were done in all patients. Other tests like arterial blood gas, liver function tests, etc., were done whenever indicated.

The management of the patients was done as per the standard management protocol with broadspectrum intravenous antibiotics, empirically, in the beginning, followed by culture sensitivity guided treatment. Apart from that, other supportive measures including oxygenation, intravenous fluids, inotropes, anticonvulsants, antipyretics, and intracranial pressure reducing agents were used whenever there was hypoxia, dehydration, shock, seizures, fever, and features of raised intracranial pressure respectively. Steroids were not used routinely. No extra tests or interventions were done to the participants, other than the standard management protocol.

The sample size was calculated using the following formula. Based on previous studies, $45 \%$ had seizure as the most common acute complication among cases of Acute Bacterial Meningitis (pneumococcal meningitis) in low- and middle-income countries. ${ }^{7-9}$

Proportion of patients with complication $(p)=45 \%$

$q=100-p=55 \%$

Taking permissible error, $L=20 \%$ of $p$

$\mathrm{L}=9 \%$

Using one sample formula, $\mathrm{n}_{0}=Z^{2} \mathrm{pq} / \mathrm{L}^{2}$

$Z$ at $95 \%$ confidence interval $=1.96$

$\mathrm{n}_{0}=\underline{1.96 \times 1.96 \times 45 \times 55}$

$9 \times 9$

$\mathrm{n}_{0}=117.38 \approx 118$

Based on the previous medical record of this hospital, the total number of cases of Acute Bacterial Meningitis 
of the age group one month to 14 years in this hospital was reported as 80 in the last year (2019).

$\mathrm{N}=80$

Corrected sample size, $\frac{\mathrm{n}=\mathrm{n}_{0}}{1+\mathrm{n}_{0} / \mathrm{N}}$
$\mathrm{n}=47.67 \approx 48$

The final sample size was taken 52 .

A convenience sampling technique was used. The patients were enrolled in the study from the day of admission and followed up daily till discharge. The various socio-demographic, clinical profile, laboratory parameters, treatment given, response to treatment, and presence of complications, if any, were noted and entered in a predesigned proforma. Other parameters like the timing of the first dose of antibiotics and the gap between the first dose of antibiotic and lumbar puncture were noted. Also, the time taken for the fever to subside was noted. Patients were divided into two groups: with complications and without complications. Complications included death, seizures, features of raised intracranial pressure, cranial nerve palsy, motor abnormalities like monoparesis, hemiparesis, or quadriparesis, and visual or hearing defects. Similarly, CT scan head abnormalities like brain oedema, subdural effusion, hydrocephalus, infarct, haemorrhage, and brain abscess were also included as complications. Patients who got discharged without the above-mentioned complications were grouped as not having complications. The data obtained were entered into the computer using the Microsoft Excel program and statistical analysis done using Statistical Package for Social Sciences (SPSS) version 20 (IBM Corp., Armonk, N.Y., USA) software. Descriptive statistics were used to analyse the data like mean, median, and standard deviation (SD). The Chi-square test was used for the analysis of categorical data and the association between the variables. Fisher's exact test and continuity correction were used as per the need of data. Quantitative data (of clinical and laboratory parameters) were compared using student $\mathrm{t}$-test or Mann-Whitney $\mathrm{U}$ test as per the need. The results are presented through tabulations and charts. Clinical, laboratory, and treatment parameters which distinguished patients with complications from patients without complications are presented through tabulations.

\section{RESULTS}

This study was done among 52 patients diagnosed as Acute Bacterial Meningitis by clinical and laboratory parameters. Patients were enrolled from the day of admission and followed up till discharge. There was a male preponderance with a male to female ratio of 2:1.
The median (Interquartile Range- IQR) age of the patients was two years $(0.3,7)$. Complications were seen in 20 (39\%) patients including four (7.7\%) deaths. The median (IQR) duration of symptoms was three days $(2,6)$, each in the group with complication and without complication respectively. There was a median (IQR) time lag of three days $(2,6)$ between the onset of symptoms and hospitalisation. However, the duration of symptoms and time lag between the onset of symptoms and hospitalisation were comparable among the group with complications and the group without complications. The number of children with malnutrition was significantly higher in the group of patients with complications ( $p$ $=0.002$ ). Also, the distribution of socio-demographic and clinical factors like age, gender, geographical area, and use of antibiotics before visiting the hospital was comparable among the two groups. None of the patients in the study had received meningococcal vaccination. The details of the baseline socio-demographic and clinical factors are mentioned in Table 1.

The patients presented with various clinical features, alone or in combination. The presence of most of these symptoms was comparable among both groups (with and without complication). Notably, the patients having loss of consciousness and ear discharge were significantly higher in the group of patients with complications ( $p=$ 0.001 and 0.04 respectively). Also, none of the patients had diarrhoea. Twenty-two (46\%) children complained of headaches. Poor feeding was described for children less than or equal to two years of age. Out of 28 patients less than or equal to two years of age, $26(50 \%)$ had poor feeding. The details of the various clinical features are given in Figure 1.

Various abnormal physical findings were noted in the patients. Anterior fontanelle was assessed for children $\leq 18$ months. Out of 23 patients, who were less than or equal to 18 months of age, a bulged fontanelle was seen in 11 (21.2\%) patients. Raised intracranial pressure was seen in $25(48.1 \%)$ patients. Similarly, cranial nerve palsy and papilloedema were seen in five (9.6\%) patients respectively. Two (3.8\%) patients had third cranial nerve palsy, while three (5.8\%) had sixth cranial nerve palsy. Similarly, visual field defect was seen in two (3.8\%) patients. The presence of respiratory distress, hypoxaemia, abnormal pupils, abnormal higher mental function at presentation, Kernig's sign, and Brudzinski sign were significantly higher in the group of patients with complications than in the group without complications. The details of the physical findings are given in Table 2. 
The mean Glasgow Coma Scale (GCS) score in the group with complications was significantly lower than in the group without complications $(p=0.001)$. All patients underwent lumbar puncture after the initiation of antibiotics. The median (IQR) time gap between hospitalisation and lumbar puncture was 13 hours $(7.25,26.75)$. The values of CSF glucose level, CSF cell count, haemoglobin level, total leukocyte count, serum sodium, potassium, urea, and plasma glucose levels were comparable in the group of patients with complications and group of patients without complications. However, the group of patients with complications had significantly higher levels of CSF protein, serum creatinine, and serum lactate levels, while this group had lower blood $\mathrm{pH}$ and platelet levels as compared to the group of patients without complications. Also, the presence of metabolic acidosis (defined as serum $\mathrm{pH}<7.35$ with serum bicarbonate $<22 \mathrm{meq} / \mathrm{l}$ ) and hyperlactataemia (defined as arterial blood lactate $>1.5 \mathrm{mmol} / \mathrm{l}$ ) were higher in the group with complications ( $p<0.001$ each). The details of the blood and CSF findings are mentioned in Table 3.

A positive CSF culture for organisms was found only in three patients $(5.8 \%)$, while five $(9.6 \%)$ had a positive blood culture. None of the patients in the group without complications had a positive CSF culture for organisms. The patients with positive blood or CSF culture were significantly higher in the group with complications ( $p$ $=0.04$ and $p=0.02$ respectively). However, the presence of organisms in urine culture was comparable among the two groups. The details of organisms yielded from different body fluids are mentioned in Table 4.

The management of the patients was done with broad-spectrum intravenous antibiotics empirically in the beginning, followed by culture sensitivity guided treatment. The most common empirical antibiotic used was a combination of ceftriaxone and vancomycin (40, 77\%) followed by a combination of meropenem and vancomycin $(6,11.5 \%)$. Anticonvulsant was used in $31(60 \%)$ patients. Fourteen patients (45.2\%) were discharged on long-term oral anticonvulsants. Drugs lowering intracranial pressure were used in 25 (48.1\%) patients. The most common intracranial pressurelowering drug used was intravenous mannitol, used in 20 (39\%) patients, followed by $3 \%$ sodium chloride, used in five $(9.6 \%)$ patients. The median (IQR) duration of use of intracranial pressure-lowering drugs was 48 hours (33, 63). Similarly, inotropes were used in 14 (27\%) patients, for a mean duration of $2.6 \pm 0.6$ days, while mechanical ventilation for respiratory support was used in 10 patients (19.2\%), for a median duration of three days $(3.4,7.5)$. Similarly, blood products were used in 15 (29\%) patients.

The total duration of hospital stay and PICU stay, respectively, were significantly higher in the group with complications ( $p=0.005, p<0.001$ respectively). Similarly, the mean time taken for defervescence in the group with complications was higher $(p<0.001)$ than that in the group without complications. The details of the time gap (hours) between hospitalisation and the first dose of intravenous antibiotic, time gap (hours) between the first dose of antibiotic and lumbar puncture, duration (days) of hospital stay and PICU stay, time taken for defervescence (days) and duration (days) of use of antibiotics is given in Table 5 .

In this study, the mortality rate was nearly eight percent $(n=4)$. During the hospital stay, the patients developed different complications. Pressure sore was present in six (11.5\%) patients. Seven (13.5\%) patients developed acute kidney injury, while four (7.7\%) acquired some form of nosocomial infection. Out of those who developed a nosocomial infection, two (3.8\%) patients each developed urinary tract infection and pneumonia respectively. Two (3.8\%) developed Acute Respiratory Distress Syndrome (ARDS), six (11.5\%) developed Multiple Organ Dysfunction Syndrome (MODS) while three (5.8\%) had Disseminated Intravascular Coagulation (DIC). None of the patients had hearing loss. CT scan head was done in 18 (34.6\%) patients, out of which 14 (26.9\%) had some abnormality. The frequency distribution of various complications is shown in Figure 2. 
Table 1: Distribution of baseline socio-demographic characteristics

\begin{tabular}{|c|c|c|c|c|c|}
\hline Characteristics & & $\begin{array}{c}\text { Complications present, } \\
\text { n (\% of total) }\end{array}$ & $\begin{array}{l}\text { Complications absent, } \\
\text { n (\% of total) }\end{array}$ & $\begin{array}{c}\text { Total, } \mathbf{n}(\% \\
\text { of total) }\end{array}$ & p-value \\
\hline \multirow{2}{*}{ Gender } & Male & $15(28.8)$ & $20(38.5)$ & $35(67.3)$ & \multirow{2}{*}{$0.35^{*}$} \\
\hline & Female & $5(9.6)$ & $12(23.1)$ & $17(32.7)$ & \\
\hline \multirow{3}{*}{ Age } & $\leq 12$ months & $8(15.4)$ & $13(25)$ & $21(40.4)$ & \multirow{3}{*}{$0.34 \dagger$} \\
\hline & 13 months - 5 year & $2(3.8)$ & $8(15.4)$ & $10(19.2)$ & \\
\hline & 6 years -14 years & $10(19.2)$ & $11(21.2)$ & $21(40.4)$ & \\
\hline \multirow{2}{*}{ Geographical area } & Terai & $14(26.9)$ & $25(48.1)$ & $39(75)$ & \multirow{2}{*}{$0.51^{*}$} \\
\hline & Hill & $6(11.5)$ & $7(13.5)$ & $13(25)$ & \\
\hline \multirow{2}{*}{ Residence } & Rural & $12(23.1)$ & $17(32.7)$ & $29(55.8)$ & \multirow{2}{*}{$0.63^{*}$} \\
\hline & Urban & $8(15.4)$ & $15(28.8)$ & $23(44.2)$ & \\
\hline Antibiotic prior to admission & Used & $10(19.2)$ & $12(23.1)$ & $22(42.3)$ & $0.37^{*}$ \\
\hline Malnutrition & Present & $15(28.8)$ & $10(19.2)$ & $25(48.1)$ & $0.002^{*}$ \\
\hline \multicolumn{2}{|l|}{ Total } & $20(38.5)$ & $32(61.5)$ & & \\
\hline
\end{tabular}

${ }^{*}$ Chi-square test; †Fisher exact test

Table 2: Abnormal physical examination findings

\begin{tabular}{|c|c|c|c|c|}
\hline Characteristics & $\begin{array}{c}\text { Complications } \\
\text { present, } \mathbf{n}(\% \text { of total) }\end{array}$ & $\begin{array}{c}\text { Complications } \\
\text { absent, } \mathbf{n} \text { (\% of total) }\end{array}$ & Total, n (\% of total) & p-value \\
\hline Respiratory distress & $13(25)$ & $11(21.2)$ & $24(46.2)$ & $0.031^{*}$ \\
\hline Hypoxemia & $7(13.5)$ & $1(1.9)$ & $8(15.4)$ & $0.002 \dagger$ \\
\hline Anaemia & $14(26.9)$ & $23(44.2)$ & $37(71.2)$ & $0.89^{*}$ \\
\hline Abnormal pupils & $10(19.2)$ & $4(7.7)$ & $14(26.9)$ & $0.003+$ \\
\hline Abnormal higher mental function & $18(34.6)$ & $14(26.9)$ & $32(61.5)$ & $0.001 \dagger$ \\
\hline Neck rigidity & $11(21.2)$ & $14(26.9)$ & $25(48.1)$ & $0.43^{*}$ \\
\hline Kernig's sign & $11(21.2)$ & $7(13.5)$ & $18(34.6)$ & $0.015^{*}$ \\
\hline Brudzinski sign & $9(17.3)$ & $6(11.5)$ & $15(28.8)$ & $0.042^{*}$ \\
\hline Bulged fontanelle & $5(9.6)$ & $6(11.5)$ & $11(21 \%)$ & $0.30+$ \\
\hline
\end{tabular}

${ }^{*}$ Chi-square test; + Fisher exact test

Table 3: Clinical and laboratory parameters of patients

\begin{tabular}{lccc}
\hline Characteristics & Complications present & Complications absent & p-value \\
\hline Glasgow Coma Scale Score (Mean \pm SD) & $10.7 \pm 2.7$ & $13 \pm 2$ & $0.001^{*}$ \\
\hline CSF glucose in mg/dl (Median (IQR) & $30(16.25,47.75)$ & $46(28.5,56.75)$ & $0.08 \dagger$ \\
\hline CSF cells in cells/mm (Median (IQR) & $70(16.25,150)$ & $62.5(30,100)$ & $0.9 \dagger$ \\
CSF protein in mg/dl (Median (IQR) & $90(56,197.5)$ & $71(31.25,100)$ & $0.04 \dagger$ \\
\hline Hemoglobin in gram/dl (Mean \pm SD) & $10.1 \pm 2.1$ & $10.5 \pm 2$ & $0.44^{*}$ \\
\hline Total Leukocyte count in cells/Cu mm & $15500(10675,18000)$ & $14500(10150,20,400)$ & $0.9 \dagger$ \\
(Median (IQR) & $190000(150000,310000)$ & $310000(210000,400000)$ & $0.04 \dagger$ \\
Platelet count in cells/Cu mm (Median (IQR) & $136.5 \pm 3.7$ & $134.5 \pm 4.1$ & $0.35^{*}$ \\
\hline Serum sodium in meq/L (Mean \pm SD) & $4.5 \pm 0.7$ & $4.3 \pm 0.6$ & $0.45^{*}$ \\
Serum potassium in meq/L (Mean \pm SD) & $27.5(19.5,44.75)$ & $0.4(0.3,0.6)$ & $0.06 \dagger$ \\
\hline Serum urea in mg/dl (Median (IQR) & $0.6(0.43,0.9)$ & $85.9 \pm 16.1$ & $0.01 \dagger$ \\
Serum Creatinine in mg/dl (Median (IQR) & $81.8 \pm 17.6$ & $7.37 \pm 0.1$ & $0.39^{*}$ \\
\hline Plasma glucose in mg/dl (Mean \pm SD) & $7.26 \pm 0.8$ & $0.5(0.3,0.8)$ & $<0.001^{*}$ \\
\hline Blood pH (Mean \pm SD) & $1.8(0.8,2)$ & $<0.001 \dagger$ \\
\hline Serum Lactate in mmol/I (Median (IQR) & &
\end{tabular}

*Student's t-test; †Mann-Whitney U test 
Table 4: Organisms in different body fluids, $\mathbf{n}(\%)$

\begin{tabular}{|c|c|c|c|c|}
\hline Organism & CSF* & Blood $^{*}$ & Urine* $^{*}$ & Total* \\
\hline Staphylococcus aureus & $2(3.8)$ & $2(3.8)$ & & $4(7.7)$ \\
\hline Streptococcus pneumoniae & $1(1.9)$ & & & $1(1.9)$ \\
\hline Acinetobacter & & $1(1.9)$ & & $1(1.9)$ \\
\hline Klebsiella pneumoniae & & $1(1.9)$ & & $1(1.9)$ \\
\hline Escherichia coli & & & $2(3.8)$ & $2(3.8)$ \\
\hline Total* & $3(5.8)$ & $4(7.7)$ & $2(3.8)$ & \\
\hline
\end{tabular}

*Percentage of total

Table 5: Timeline of treatment received

\begin{tabular}{lccc}
\hline Characteristics & Complications present & Complications absent & p-value \\
\hline $\begin{array}{l}\text { Time gap (hours) between hospitalisation and the } \\
\text { first dose of intravenous antibiotic (Mean } \pm \text { SD) }\end{array}$ & $1.1 \pm 0.3$ & $1.13 \pm 0.3$ & $0.78^{*}$ \\
\hline $\begin{array}{l}\text { Time gap (Hours) between the first dose of antibiotic } \\
\text { and lumbar puncture (Median/IQR) }\end{array}$ & $17(8,25)$ & $10.5(5.25,24)$ & $0.73 \dagger$ \\
\hline Duration (Days) of hospital stay (Mean \pm SD) & $14.5 \pm 3.6$ & $11.1 \pm 2.3$ & $0.005^{*}$ \\
\hline Duration (Days) of PICU stay (Median/IQR) & $5(4,9)$ & $2.5(2,5.75)$ & $<0.001 \dagger$ \\
\hline Time taken for defervescence (Mean \pm SD) & $6.42 \pm 2.4$ & $3.81 \pm 1.2$ & $<0.001^{*}$ \\
\hline Duration (Days) of antibiotic use (Mean \pm SD) & $14.6 \pm 6.4$ & $11.16 \pm 2$ & $0.007^{*}$
\end{tabular}

"Student's t-test; † Mann-Whitney U test

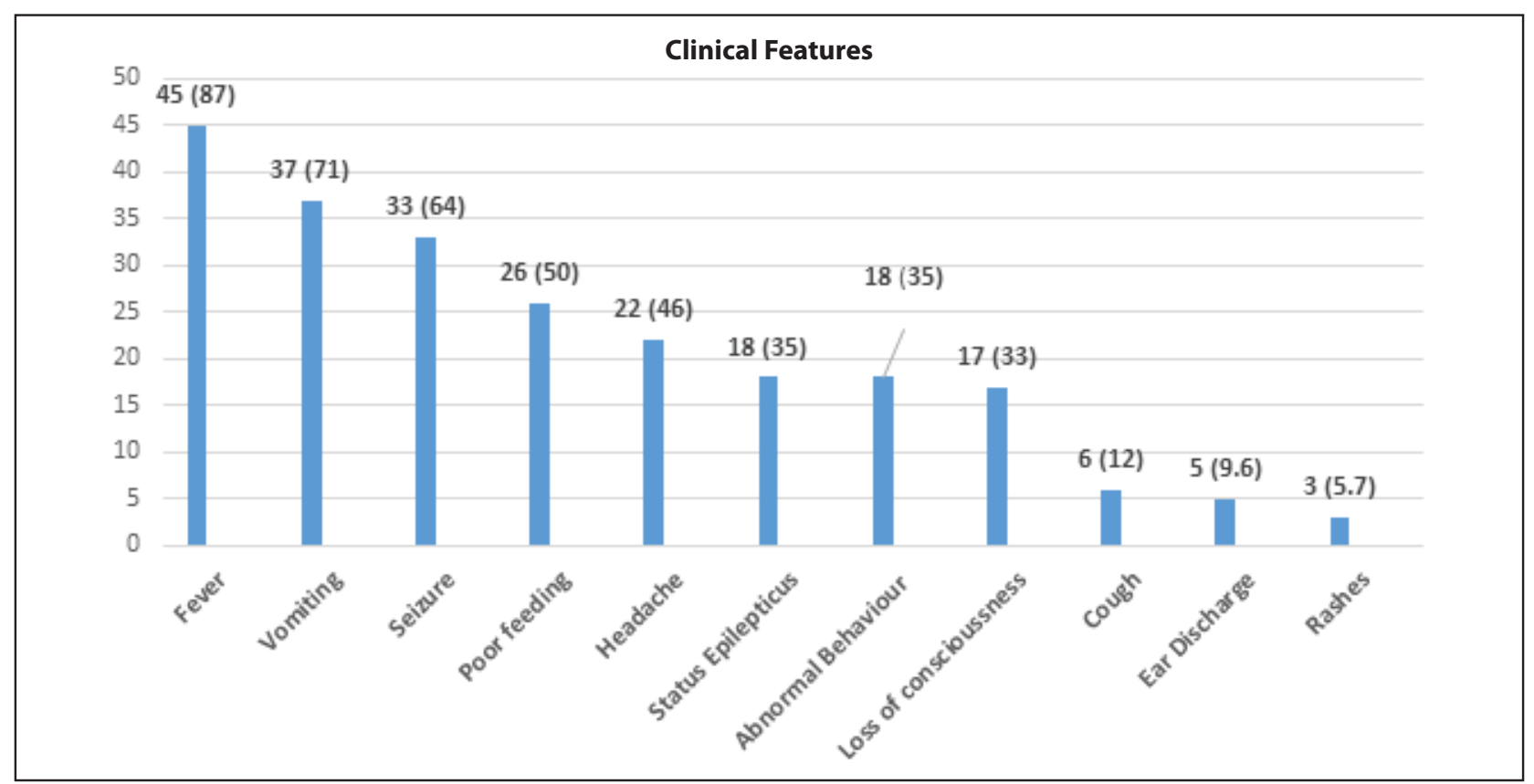

Figure 1: Clinical features of patients with acute bacterial meningitis, $\mathbf{n}(\%)$ 


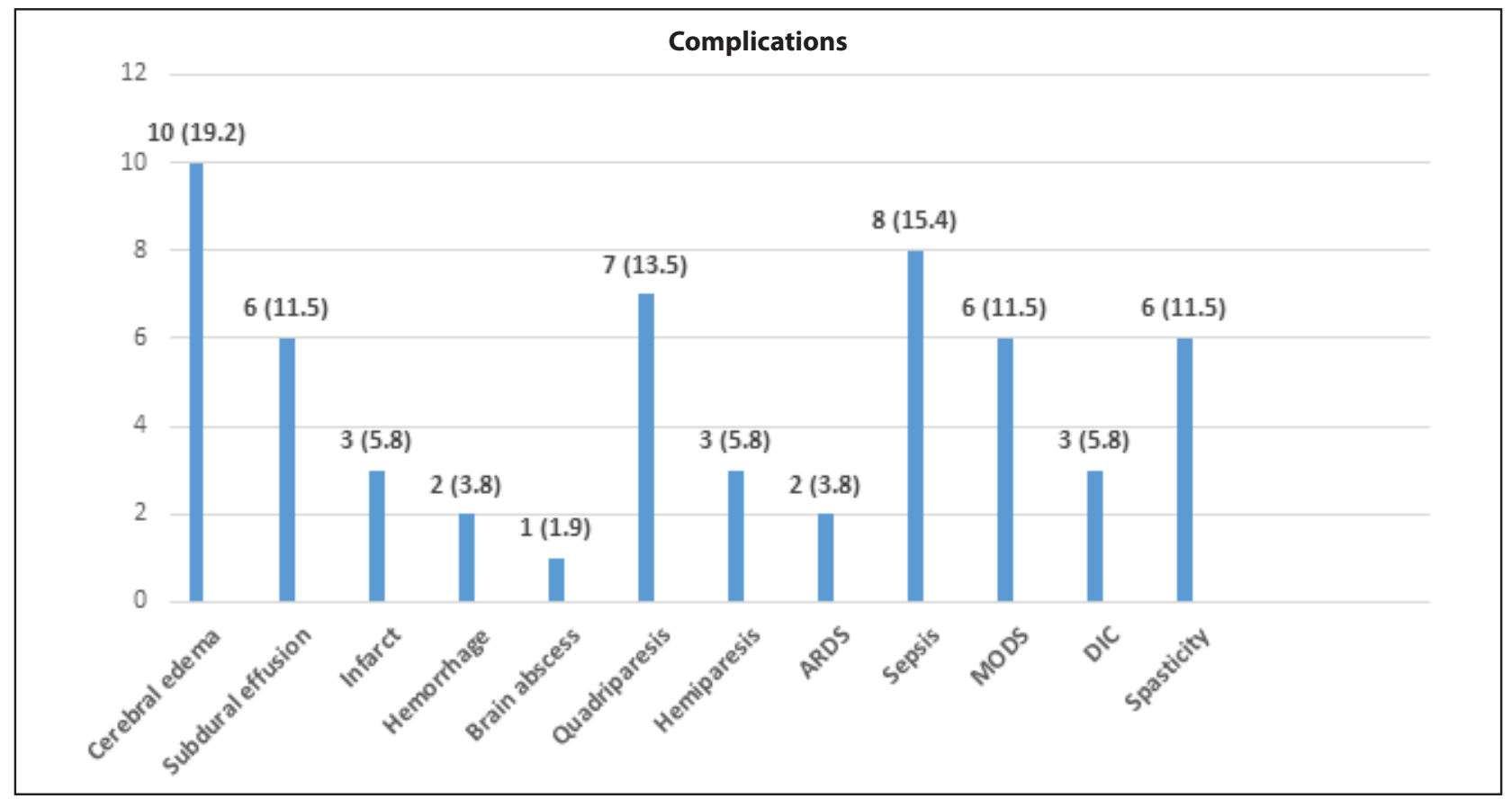

Figure 2: Complications encountered among patients, $\mathbf{n}(\%)$

\section{DISCUSSION}

Various socio-demographic, clinical, and diagnostic parameters of 52 children with a diagnosis of acute bacterial meningitis aged one month to 14 years of age were studied. There was a male preponderance in this study, and the majority of the children belonged to the under five year age group, a finding similar to other studies. ${ }^{10-13}$ However, in a study done by Shrestha et al. the majority of children were above five years of age. ${ }^{14}$ The reason behind the higher prevalence of meningitis in younger children could be a lower immunity and incomplete immunisation series in this age group. The median time lag between symptom onset and hospitalisation was three days in this study. More than half of the study population were from rural areas. The possible reasons could be low socioeconomic status, overcrowding, and lack of timely access to proper health facilities.

In this study, nearly $43 \%$ of patients had received antibiotics prior to hospitalisation for this illness. In contrast, Abdelrahim et al. observed that none of the patients in their study had received antibiotics prior to hospital visit. ${ }^{11}$ The indiscriminate use of antibiotics in current setup might be a reason.

The patients presented with different clinical features. Fever, headache, and vomiting were the predominant symptoms. Two-third of the patients in this study had seizures, similar to what Fitzwater et al. observed. ${ }^{15}$ It was observed in the study that one-third of the patients had a loss of consciousness and $11 \%$ of patients had a bulged fontanelle. However, Fitzwater et al. in their series observed a lesser incidence of loss of consciousness (14\%) and bulged fontanelles (6\%), as compared to this study. ${ }^{15}$ Similarly, the incidence of cranial nerve palsy in this study (10\%) was lesser than that observed by Moghtaderi et al. ${ }^{16}$ The presence of meningeal signs in this study (48\%) were lower in comparison to the findings made by Fitzwater et al. (60\%). ${ }^{15}$

In the present study, all patients underwent lumbar puncture after administration of antibiotics. Dissimilar to this were the findings made by Obiero et al. and Kanegaye et al. who observed that only $30-34 \%$ of patients received antibiotics before lumbar puncture. ${ }^{10,17}$ The reason behind this could be an obvious delay in the lumbar puncture due to logistic reasons in the emergency room. Anticipating this usual delay, antibiotic administration was not deferred. The median time taken for lumbar puncture after admission in this study was 13 hours. Nearly $60 \%$ of the patients in this study had a CSF cell count of more than 50, similar to what Obiero et al. observed. ${ }^{10}$ The median CSF glucose in this study (48) was comparable to the findings of other studies. ${ }^{10}$ However, a lower CSF total cell count and protein were observed in the current study compared to other studies. The reason for the lower CSF total cell count and protein 
in this study can be attributed to the use of antibiotics before performing a lumbar puncture. Being a referral centre, most of the patients have received intravenous antibiotics prior to presentation. Also, none of the CSF samples yielded a positive result on gram staining. In the same context, we observed that culture of CSF yielded organism in only six percent cases, contrary to what most other authors described (10-20\%). 10,12,14,18 The CSF culture positivity in the study by Nwadioha et al. was similar to the findings of present study $(3 \%) .{ }^{19}$ The reason for the low yield of organisms in CSF culture and the absence of organisms in gram stain might be the prior use of systemic antibiotics that could have altered the typical CSF picture. In this study, CSF samples of two patients had Staphylococcus aureus while one had Streptococcus pneumoniae. There was a variation in the CSF culture detection in different studies. Most of the studies had Streptococcus pneumoniae as the most common organism causing meningitis. ${ }^{10,12,13,19}$ Abdelrahim et al. reported Neisseria as the most common organism isolated in CSF, while Debnath et al. reported Klebsiella as the major organism. ${ }^{11,20}$ The incidence of Haemophilus influenza $b$ seems to be decreasing slowly over the past few years, the reason being the inclusion of Haemophilus influenza $b$ in the routine immunisation schedule of different countries worldwide. Similarly, only eight percent of the patients had a positive blood culture in this study, similar to the findings made by Debnath et al. ${ }^{20}$ Contrary to this, Obiero et al. detected a $34 \%$ blood culture positivity in their study. ${ }^{10}$ The reason for the low yield of blood culture might be the indiscriminate use of antibiotics in this part of the world.

The median duration between hospitalisation and antibiotic administration was one hour in this study, which is in harmony with the findings of Ciofi degli Atti et al. ${ }^{21}$ The median duration of hospitalisation roughly corresponds to the duration of antibiotics given for a specific organism. In this study, most of the antibiotic regimens were given empirically for a median duration of 10-14 days. This is similar to the findings of Ciofi degli Atti et al. ${ }^{21}$

CT scan head was done in 18 (34.6\%) patients, out of which 14 (26.9\%) had some abnormality. The incidence of hydrocephalus and brain infarct in this study $3.8 \%$ and $5.8 \%$ ) was lesser than the findings observed by Singhi et al. (15\% and 8.75\%). ${ }^{22}$ Similarly the incidence of brain abscess $(1,1.9 \%)$ was lower in this study, as was the finding made by Rasul et al. (4\%). ${ }^{13}$ However, the patients with cerebral oedema, as demonstrated in CT head were higher in this study $(10,19.2 \%)$ as compared to the observations of Rasul et al. (8.3\%). ${ }^{13}$ Also, the proportion of patients having haemorrhage on CT head, in this study were comparable to the study of Ciofi degli Atti et al. ${ }^{21}$ The proportion of patients with abnormality in CT scan head might be due to two reasons, first being the early introduction of systemic antibiotics leading to a lesser number of complications; the second being the lesser number of patients in whom CT scan head was done, may be due to financial or logistic reasons. In this study, there was a higher incidence of sepsis, Disseminated Intravascular Coagulation (DIC), and nosocomial infection (15.4\%, 5.8\%, and $7.7 \%$ ) as compared to the findings of Ciofi degli Atti et al. ( 3.5\%, 5.9\%, and 1.2\%). ${ }^{21}$ The incidence of neurologic complications in the current study was $38.5 \%$. Different studies have reported wide variation in the occurrence of neurologic complications from $8.5 \%$ to $42 \% .^{12,13,21,23}$ However, we estimated the inhospital complications only, and could not follow the patients' post-discharge. This could have underestimated the actual complication rate.

In the present study, different factors like malnutrition, loss of consciousness, ear discharge, abnormal pupil, hypoxemia, abnormal higher mental function, low blood $\mathrm{pH}$, hyperlactatemia, high CSF protein, positive CSF and blood culture, and PICU admission, were significantly more in the patients with complications than in the group of patients without complications. Other studies observed that different factors like younger age, seizure, focal neurological signs, abnormal CT head findings, cranial nerve palsy, positive CSF culture deteriorating consciousness, hypoglycorrhachia were associated with adverse outcomes. ${ }^{22,23}$

This study has certain limitations. The smaller sample size affected the utility of multivariate logistic regression. The patients were followed up till discharge only, hence in-hospital complications could only be studied. A larger study duration could enable us to follow up the patients in the outpatient settings for a longer period of time to assess for other related and important complications like developmental delay, behavioural disturbances, epilepsy, etc. Also, prior use of antibiotics masked some of the clinical and laboratory parameters in the patients. A similar study with larger sample size and longer study duration could be done in the future to look for longterm complications and find the association of different factors with the occurrence of such complications.

\section{CONCLUSION}

The study showed a male preponderance. The most affected age group was infancy. Complications were 
seen in nearly half of the patients. Fever, vomiting, seizure, and headache were the most common presenting symptoms. The complication rate was higher in patients with prolonged fever, malnutrition, loss of consciousness, ear discharge, presence of meningeal signs, abnormal pupil, high cerebrospinal fluid protein, positive cerebrospinal fluid, and blood culture, low blood $\mathrm{pH}$, and hyperlactataemia. The above findings could guide the clinician in proper management, prevention of such complications, and prognostication of the patients.

\section{REFERENCES}

1. Swanson D. Meningitis. Pediatr Rev. 2015 Dec;36(12):514-24; quiz 525-6. [PubMed | Full Text |DOI]

2. Watt JP, Wolfson LJ, O'Brien $\mathrm{KL}$, Henkle E, DeloriaKnoll M, McCall $\mathrm{N}$ et al. Hib and Pneumococcal Global Burden of Disease Study Team. Burden of disease caused by Haemophilus influenzae type $b$ in children younger than 5 years: Global estimates. Lancet. 2009 Sep 12;374(9693):903-11. [PubMed | Full Text | DOI]

3. O'Brien $\mathrm{KL}$, Wolfson LJ, Watt JP, Henkle E, DeloriaKnoll M, McCall N, et al. Burden of disease caused by Streptococcus pneumoniae in children younger than 5 years: Global estimates. Lancet. 2009 Sep 12;374(9693):893-902. [PubMed | Full Text | DOI]

4. Kim KS. Acute bacterial meningitis in infants and children. Lancet Infect Dis. 2010 Jan;10(1):32-42. [PubMed | Full Text | DOI]

5. Mann K, Jackson MA. Meningitis. Pediatr Rev. 2008 Dec;29(12):417-29; quiz 430. [PubMed | Full Text | DOI]

6. Shahan B, Choi EY, Nieves G. Cerebrospinal Fluid Analysis. Am Fam Physician. 2021 Apr 1;103(7):422-

8. Erratum in: Am Fam Physician. 2021 Jun 15;103(12):713. [PubMed | Full Text]

7. Zainel A, Mitchell $H$, Sadarangani M. Bacterial meningitis in children: Neurological complications, associated risk factors, and prevention. Microorganisms. 2021 Mar 5;9(3):535. [PubMed | Full Text | DOI]

8. Casella EB, Cypel S, Osmo AA, Okay Y, Lefèvre $\mathrm{BH}$, Lichtig I, et al. Sequelae from meningococcal meningitis in children: A critical analysis of dexamethasone therapy. Arq Neuropsiquiatr. 2004 Jun;62(2B):421-8. [PubMed | Full Text | DOI]

9. King BA, Richmond P. Pneumococcal meningitis in Western Australian children: Epidemiology, microbiology and outcome. J Paediatr Child Health. 2004 Nov;40(11):611-5. [PubMed | Full Text | DOI]

\section{ACIKNOWLEDGEMENTS}

The authors are thankful to those patients and their parents who had given consent to participate in this study. The authors would like to express their gratitude to all the healthcare workers and supporting staff of paediatric ward and PICU for their cooperation.

Conflict of interest: None

Source(s) of support: None

10. Obiero CW, Mturi N, Mwarumba S, Ngari M, Newton $C R$, van Hensbroek $M B$ et al. Clinical features of bacterial meningitis among hospitalised children in Kenya. BMC Med. 2021 Jun 4;19(1):122. [PubMed | Full Text | DOI]

11. Abdelrahim NA, Fadl-Elmula IM, Ali HM. Bacterial meningitis in Sudanese children; critical evaluation of the clinical decision using clinical prediction rules. BMC Pediatr. 2019 Sep 6;19(1):319. [PubMed | Full Text | DOI]

12. Sigaúque $B$, Roca $A$, Sanz $S$, Oliveiras I, Martínez M, Mandomando I, et al. Acute bacterial meningitis among children, in Manhiça, a rural area in Southern Mozambique. Acta Trop. 2008 Jan;105(1):21-7. [PubMed | Full Text | DOI]

13. Rasul CH, Zaman MA, Hossain MJ, Nasrin E, Rahman M. Outcome and prognostic factors of acute meningoencephalitis in children of Southern Bangladesh. Sri Lanka J Child Health. 2013;42(1):2732. [Full Text | DOI]

14. Shrestha, RG, Tandukar S, Ansari S, Subedi A, Shrestha A, Poudel R, et al.. Bacterial meningitis in children under 15 years of age in Nepal. BMC Pediatr. 2015 Aug 19;15:94. [PubMed | Full Text | DOI]

15. Fitzwater SP, Ramachandran $P$, Nedunchelian K, Kahn G, Santosham M, Chandran A. Bacterial meningitis in children $<2$ years of age in a tertiary care hospital in South India: an assessment of clinical and laboratory features. J Pediatr. 2013 Jul;163(1 Suppl):S32-7. [PubMed | Full Text | DOI]

16. Moghtaderi A, Alavi-Naini R, Rashki S. Cranial nerve palsy as a factor to differentiate tuberculous meningitis from acute bacterial meningitis. Acta Med Iran. 2013 Mar 16;51(2):113-8. [PubMed | Full Text]

17. Kanegaye JT, Soliemanzadeh P, Bradley JS. Lumbar puncture in pediatric bacterial meningitis: defining the time interval for recovery of cerebrospinal fluid pathogens after parenteral antibiotic pretreatment. Pediatrics. 2001 Nov;108(5):1169-74. Erratum in: Pediatrics 2002 Sep;110(3):651. [PubMed | Full Text] 
18. Ramakrishnan M, Ulland AJ, Steinhardt LC, Moisi JC, Were F, Levine OS. Sequelae due to bacterial meningitis among African children: a systematic literature review. BMC Med. 2009 Sep 14;7:47. [PubMed | Full Text | DOI]

19. Nwadioha SI, Nwokedi EO, Onwuezube I, Egesie $\mathrm{JO}$, Kashibu E. Bacterial isolates from cerebrospinal fluid of children with suspected acute meningitis in a Nigerian tertiary hospital. Niger Postgrad Med J. 2013 Mar;20(1):9-13. [PubMed | Full Text]

20. Debnath DJ, Wanjpe A, Kakrani V, Singru S. Epidemiological study of acute bacterial meningitis in admitted children below twelve years of age in a tertiary care teaching hospital in Pune, India. Med J DY Patil Univ. 2012;5:28-30. [Full Text]
21. Ciofi degli Atti $M$, Esposito $S$, Parola $L$, Ravà L, Gargantini G, Longhi R, et al. In-hospital management of children with bacterial meningitis in Italy. Ital J Pediatr. 2014 Nov 14;40:87. [PubMed | Full Text | DOI]

22. Singhi $P$, Bansal A, Geeta $P$, Singhi S. Predictors of long term neurological outcome in bacterial meningitis. Indian J Pediatr. 2007 Apr;74(4):369-74. [PubMed | Full Text | DOI]

23. Kuti BP, Bello EO, Jegede TO, Olubosede O. Epidemiological, clinical and prognostic profile of childhood acute bacterial meningitis in a resource poor setting. J Neurosci Rural Pract. 2015;6(4):54957. [PubMed | Full Text | DOI] 